\title{
Epistemologias plurais: pensando as ciências da comunicação desde a América Latina
}

\section{Plural Epistemologies: thinking the communication sciences from Latin America risk}

\author{
Alberto Efendy Maldonado G. de la Torre \\ Programa de Pós-Graduação em Ciências da Comunicação \\ da Universidade do Vale do Rio dos Sinos, São Leopoldo, RS, \\ Brasil \\ ORCID: 0000-0002-5704-4544 \\ <efendymaldonado@gmail.com>
}

\author{
Julherme José Pires \\ Programa de Pós-Graduação em Ciências da Comunicação \\ da Universidade do Vale do Rio dos Sinos, São Leopoldo, RS, \\ Brasil \\ ORCID: 0000-0002-3253-9663 \\ <julherme.pires@gmail.com>
}

\section{Como citar este artigo (How to cite this article): \\ TORRE, Alberto Efendy Maldonado Gómez de la; PIRES, Julherme José. Epistemologias plurais: pensando as ciências da comunicação desde a América Latina. Revista Famecos, Porto Alegre, v. 25, n. 3, p. 1-18, setembro, outubro, novembro e dezembro de 2018: ID30108. DOI: http://dx.doi.org/10.15448/1980-3729.2018.3.30108.}

\section{RESUMO}

Neste artigo, problematizamos as questões envolvidas com a formação de novas epistemologias de pesquisa, especialmente da área das ciências da comunicação, a partir do contexto latino-americano. Localizamos e esmiuçamos o conceito de epistemologia, sua interrelação com o problema do conhecimento e as ciências avançadas. Problematizamos as epistemologias fundantes dos campos das ciências humanas, de forma diacrônica, e nos aprofundamos na vertente da comunicação. A partir de uma ampla pesquisa bibliográfica, pensamos epistemologicamente a investigação científica em comunicação a partir das óticas solidária e cidadã na América Latina. E, por fim, articulamos essas problemáticas e suscitamos a busca por práxis cientificas com a finalidade de transformar nossa região, um dos papéis determinantes que podem enriquecer nosso campo de pesquisa e a elevar sua relevância.

Palavras-chave: Epistemologia. Comunicação. América Latina.

\begin{abstract}
In this article, we discuss the issues involved in the formation of new research epistemologies, especially in the field of communication sciences, from the Latin American context. We localize and explore the concept of epistemology, its interrelation with the problem of knowledge and the advanced sciences. We problematize the foundational epistemologies of the human sciences fields, in a diachronic way, and we delve into the aspect of communication. From a broad bibliographical research, we think epistemologically the scientific investigation in communication from the solidarity and citizen perspectives in Latin America. And, finally, we articulate these problems and raise the search for scientific praxis with the purpose of transforming our region, one of the determining roles that can enrich our field of research and increase its relevance.
\end{abstract}

Keywords: Epistemology. Communication. Latin America.

\section{Introdução}

Enquanto nos encaminhamos para o final da segunda década do século XXI, vislumbramos um mundo que, em vez de apresentar concretizações de laços de paz e fraternidade, exibe um adensamento de conflitos internacionais e o aumento da desigualdade de renda. Ao contrário das ciências "exatas", que apresentam seu potencial, inimaginável até pouco tempo, na criação de artefatos técnicos capazes de revolucionar os mais diversos campos sociais, as ciências humanas estão muito aquém de seus potenciais de aprimorar as relações sociais, 
culturais, políticas e econômicas. As teorias aceitas nos meios hegemônicos têm representado interesses análogos ao capitalismo, servindo como instrumento de alargamento do marketing para consumo, ao divulgar pragmáticas de liberdade, dentro uma racionalidade funcional de progresso. Essas teorias decodificadas se mostram como renovações de lógicas ultrapassadas, positivistas, liberais, na contramão do que se tem produzido de melhor nas universidades integrativas da América Latina. Essas teorias representam a falta de uma racionalidade plural e apontam um estamento totalitarista de mercado.

Neste artigo, apontamos a necessidade da invenção de novas epistemologias de pesquisa a partir de uma ampla pesquisa teórica. Nutrimos este texto com dezenas de autores que pensam epistemologicamente a ciência, com uma dupla direção do universal ao pontual: de todas as ciências às ciências da comunicação; e das ciências no mundo às ciências na América Latina. Trata-se de uma problematização também transdisciplinar em relação às ciências, com vistas à formação de uma práxis científica, enriquecida para a transformação social de nossa região. Ainda vivemos numa época de fortes algemas teóricas, imputadas por ideologias históricas, sob as quais se fundamentam as principais escolas científicas, voltadas quase que unicamente às teorias nortenhas, de "países desenvolvidos"- sob a ótica dos indicadores internacionais. Há ignorância e desrespeito em relação a outros conhecimentos e, consequentemente, um estreitamento das pesquisas científicas.

As epistemologias trazidas para este texto nos ajudam a pensar desde o problema do conhecimento, sua gênese no pensamento humano, até os paradigmas hegemônicos e aqueles nos quais são baseadas as pesquisas e as relações sociais nas suas multidimensões. Propomos uma visão crítica, articulando essas epistemologias, na costura de uma teoria epistemológica para pensarmos as ciências da comunicação na América Latina. Entendendo, é claro, as ciências no plural, dotadas de ideologia, discurso e poder. Nesse sentido, busca-se o estabelecimento de uma vertente epistemológica que privilegie a cidadania, nas suas mais variadas expressões, especialmente a cidadania científica e a cidadania comunicativa. Problematização essa fortemente ancorada na história e na filosofia das ciências da comunicação, incluindo seus processos organizadores da vida social na região. É hora de repensar os processos midiáticos diante de tamanha crise de credibilidade, de distanciamento do interesse público, de atendimento à financeirização e às oligarquias, em favor de novas formas comunicativas, disruptivas, coletivas, comunitárias, inclusivas e solidárias.

As problematizações construídas aqui estão ancoradas no problema da hegemonia da financeirização sobre todos os aspectos da vida, e de uma alternativa de independência a este modelo, o da cidadania. O neoliberalismo 
apresenta-se, entretanto, como uma forma voraz de exclusão e destruição de direitos humanos e sociais. O campo científico dos países começa a ser minado por essa política econômica, o que gera a necessidade de falarmos sobre a cidadania e a cidadania científica. Aqui, compreendemos a cidadania como o respaldo e a universalização de direitos e oportunidades, a criação contínua de processos democráticos, de valorização do espaço público, de civilidade e, acima de tudo, o respeito à pessoa humana e ao meio ambiente. A cidadania científica se dá a partir da criação de oportunidades para sujeitos pesquisadores, a partir da universalização da educação, e da incorporação da pluralidade de epistemologias presentes nas extensões da história das civilizações e do território global. Falamos aqui sobre ciência e solidariedade.

\section{Construindo uma intersecção lógica}

Entre a origem do pensamento e a operacionalização das teorias, há um devir gnosiológico, uma consistência subsidiária capaz de produzir o solo da pesquisa e se manifesta desde os primeiros passos, até seu resultado final. Estamos falando sobre um problema de conhecimento da ciência, do pensar e do agir científico. Propor uma epistemologia, antes de tudo, é preparar o terreno da pesquisa com cuidado, de modo que ela produza lógicas plurais de forma frutífera. Peirce $(1997$, p. 16) afirma que o melhor para a ciência é um método não humano, "algo sobre o qual o nosso pensamento não tem efeito". Essa proposição é, ironicamente, a gênese de todo o seu pensamento epistêmico, um conhecimento supostamente visualizado nas ciências exatas e articulado nas novas ciências da dobra dos séculos XIX para o XX. Mas, como se dá a produção de conhecimento? Como participam as subjetividades dos cientistas e de suas comunidades nessa produção? O que há por trás do método científico? E a quais ideologias servem os paradigmas?

Em sua obra, Cassirer (1993) nos convida para uma viagem ao interior do conhecimento. E logo de cara, nos aponta um problema epistemológico para pensar o conhecimento, o problema de seu cerceamento definitivo. A filosofia moderna tem estabelecido fronteiras duras em relação ao que é conhecimento e o que não é, e a proposta ideológica por trás disso é ameaçadora à transdisciplinaridade, beneficia apenas o modelo positivista como operação macro de ciência. O conhecimento évisto pornós em sua operação de construção, como um processo constante, desde a pré-história da humanidade, passando pela sua caracterização filosófica na Grécia Antiga, até ingressarmos no século XXI. Em vez de negarmos o devir do conhecimento, deveríamos voltar às fontes, abrirmos seu conceito. "A tarefa da epistemologia consiste em conhecer este devir e analisar todas as etapas de sua estruturação" (Japiassu, 1991, p. 27). 
O conhecimento para Cassirer (1993, p. 62) não é neutro, mas, visto como um centro de preocupações, é a "força criadora fundamental, primordial, sobre a qual descansa a estrutura da cultura intelectual e moral em seu conjunto" (tradução nossa)'. É por isso que restringir o conceito de conhecimento ao científico, limitá-lo, reduzi-lo ao cálculo e cercá-lo nos muros da disciplina são formas de precarizar, adestrar e esterilizar a produção de conhecimentos conceito que transferido para o plural, para o autor, significa dar-lhe uma noção mais agregadora. A compreensão do conhecimento ganha corpo quando notamos que ele está extremamente articulado com o tempo e o lugar de onde é produzido, é dotado de lugares de fala, de postulados acadêmicos, econômicos, políticos, religiosos e culturais. A inocência produz uma visão de que o conhecimento é absoluto, e esse é o primeiro passo para o estabelecimento de dogmas universais, característicos de outros campos do saber, dos quais precisamos afastar nossas pesquisas.

Compreendemos a epistemologia como dimensão transformadora da ciência, uma angulação múltipla de campos - filosofia, sociologia, psicologia, antropologia, economia e história da ciência. Ela atravessa todas as dimensões da pesquisa, da teórica à técnica, ela articula esses saberes, os coloca num plano comum. Trata-se também de uma dialética com o senso comum, para produzir bons sensos, fundamenta rupturas, subversões com as institucionalidades. A epistemologia é justamente a dimensão que põe o conhecimento em crise, o pressiona para provocar uma multiplicidade teórica, o coloca em contato com outros saberes, com a finalidade de produzir novas lógicas científicas. "Essencialmente, a epistemologia é o estudo crítico dos princípios, das hipóteses e dos resultados das diversas ciências. Semelhante estudo tem por objetivo determinar a origem lógica (não psicológica) das ciências, seu valor e seu alcance objetivos" (Japiassu, 1991, p. 25).

Para Japiassu (1991), a epistemologia é indispensável, sem ela seria como se, em vez fazer de pesquisa, meditássemos no vazio, à deriva na escuridão do senso comum ou da aleatoriedade infinita. "É a epistemologia que nos permite discernir a história dos conhecimentos científicos que já estão superados e a dos que permanecem atuais (ou sancionados), porque permanecem atuantes e colocando em marcha o processo científico"(Japiassu, 1991, p. 33).Epistemologia, porém, é um conceito flexível, é também um meio para "estudar a gênese e a estrutura dos conhecimentos científicos" (Japiassu, 1991, p. 38); não quer ditar o que é certo e o que é errado, mas busca na transdisciplinaridade uma visão

1 Original: La fuerza creadora fundamental, primordial, sobre que descansa la estructura de la cultura intelectual y moral en su conjunto. 
mais ampla dos processos científicos, dando a devida atenção à intervenção de processos de outras naturezas nas ciências. Para Japiassu (1991, p. 38), "ela procura estudar esta produção dos conhecimentos, tanto do ponto de vista lógico, quanto dos pontos de vista linguístico, sociológico, ideológico".

Há uma diversidade de epistemologias científicas, tratadas por distintos pensadores e correntes. Essa pluralidade foi problematizada por Norris (2007), quem levantou diferenças e articulações entre várias conceituações epistemológicas. Para ele, a busca pelo essencialismo para resolver o problema do conhecimento foi uma armadilha em que as linhagens filosóficas cartesiana e humeana caíram. "Seja à quimera racionalista (cartesiana) das 'ideias claras e distintas', seja à noção empirista humeana dos dados dos sentidos como uma justificação ou defesa em última instância contra a dúvida epistemológica" (Norris, 2007, p. 22), ambas acabaram produzindo abordagens epistemológicas incompletas.

\begin{abstract}
Está claro que os epistemólogos - inclusive aqueles de convicção realista - têm muito a aprender com as abordagens adotadas por alguns sociólogos do conhecimento e historiadores culturais da ciência. Afinal de contas, esses investigadores produziram alguns estudos de caso altamente informativos concernentes aos detalhes cotidianos da 'vida no laboratório', sobre o papel dos fatores ideológicos na origem ou na decisão das disputas científicas, bem como sobre os vários interesses motivadores (políticos, religiosos, profissionais, etc.) que afetam o modo como os cientistas trabalham ou pensam. (Norris, 2007, p. 214).
\end{abstract}

Japiassu (1991), por outro lado, reúne epistemologias frutíferas para se pensar a pesquisa. A começar pela epistemologia genética de Piaget, que se pergunta sobre o desenvolvimento do ser humano, desde criança, como sua inteligência se constrói, seus modos de operação com os objetos, as funções motoras de seu corpo, "até a elaboração dos conceitos que estão na origem dos conhecimentos da física, da matemática, e etc." (Japiassu, 1991, p. 56). A epistemologia histórica de Bachelard, para quem é fundamental a investigação sobre os valores ideológicos que intervêm na prática científica; as interrelações entre a poética, a arte e a ciência, elevando a dimensão da estética ao nível de conhecimento legítimo. A epistemologia racionalista-crítica de Popper, centrada nos modos de refutação e no valor da experimentalidade; para Popper $(1975$, p. 32), a melhor teoria era aquela "mais bem testada". A epistemologia arqueológica de Foucault, que propõe a escavação dos "arquivos da cultura" para a compreensão teórica, de modo a desenterrar a teoria e verificar o que está junto dela. 
A proposta de Japiassu (1991, p. 138) é uma epistemologia crítica, focada na "reflexão histórica feita pelos cientistas sobre os pressupostos, os resultados, a utilização, o lugar, o alcance, os limites e a significação socioculturais da atividade científica". Trata-se de uma metacrítica epistemológico-científica, ao próprio fazer técnico-científico e ao modelo de funcionamento das instituições acadêmicas. É também a compreensão e a desconstrução das lógicas de poder, do imperialismo da ciência prestigiada, das línguas e linguagens hegemônicas. A ciência para Japiassu (1991) precisa desgrudar-se do conceito de progresso, pois má administrada, ela pode ser a própria ruína.

O pensamento epistemológico nos desafia a ultrapassar as lógicas formais, produzir lógicas paraconsistentes, multiléticas, de observação dos condicionamentos. Essasnovas lógicas podemestarfundamentadase orientadas pelo entendimento cultural da ciência, porque para além de seres humanos, somos sujeitos, e sujeitos de uma linguagem comunicacional estruturada. Para Habermas (2000), esse é o princípio que nos separa dos chimpanzés, e também é o princípio organizador de nossas experiências intelectuais, sob o ponto de vista de que a racionalidade é produzida não apenas nas ofertas cognitivas e instrumentais, mas nas dimensões prática-moral e estética-expressiva. É o que a ciência precisa entender, o humano-sujeito como produtor e produto de contextos, para se autocompreender. Em paralelo com esse autor, Morin (2008) fala em espírito, referindo-se a dimensão racional do ser humano, da reflexividade e da cogitação. Para esse pensador, o "espírito está no mundo que está no espírito" (Morin, 2008, p. 233). Ou seja, as dimensões do humano/sujeito estão indelevelmente articuladas às propriedades do restante da natureza/sociedade.

Há vários modelos de operação científica diante dessas condições de atravessamento do mundo na pesquisa. É Wittgenstein quem propõe a ideia de que"vários métodos diferentes de verificação podem ser aceitos [...] depende de condições definidas que nós determinamos" (Haller, 1990, p. 31). Isso é basilar para as afirmações científicas e suas condições. É esse o sentido de atuação filosófica na pesquisa, o de clarificar a lógica de pensamentos e enxergar as intervenções da linguagem e da técnica no mundo da vida.

O Círculo de Viena, onde essas ideias de Wittgenstein ganharam corpo, é um exemplo de comunidade científica frutífera descrita por Kuhn (1998). A primeira metade do século $X X$ foi uma época em que muitos paradigmas balançavam a ciência, mas alguns pensadores notaram que era preciso unir forças em prol de novos paradigmas. Entretanto, o modo mais qualificado para essa transformação na ciência é justamente a articulação entre paradigmas existentes. "Se não tem o poder de considerar os eventos retrospectivamente, torna-se difícil encontrar outro critério que revele tão claramente um campo de 
estudos tornou-se uma ciência" (Kuhn, 1998, p. 42). A preocupação do cientista deve estar alocada no sentido de trabalhar com os paradigmas, mas de uma forma que induza a mudança nesses paradigmas; é assim que a ciência progride. "O significado das crises consiste exatamente no fato de que indicam que é chegada a ocasião para renovar os instrumentos" (Kuhn, 1998, p. 105). Assim como na época da escola austríaca, as ciências econômicas, sociais, políticas, culturais e da comunicação do século XXI precisam de um salto dialético para evitar um retrocesso das civilizações.

\section{As ciências da comunicação}

Foi no início do século XIX, em detrimento de outras áreas, no período em que o termo ciência ganhava o status atual, que as ciências naturais convocaram para si a exclusividade desse título. Suas descobertas, seguidas de um deslumbramento com o "progresso da humanidade", e suas notáveis contribuições para a industrialização, deram aos pesquisadores dessa área o prestígio necessário para obter investimentos e a divulgação privilegiada. A história intelectual do século XIX, explicam Wallerstein e a Comissão Gulbenkian (1996, p. 23), é marcada por um "processo de disciplinarização e profissionalização do conhecimento", em que havia uma contínua tensão entre as áreas das "humanidades e das artes" e as "ciências". Nesse período, ganha propulsão um modelo newtoniano adaptado às humanidades, o da "física social". "A ciência positiva visava a libertação total relativamente à teologia e à metafísica, bem como a todos os demais modos de 'explicação' da realidade" (Wallerstein e outros, 1996, p. 28). As ciências sociais fundaram-se orientadas sob a égide dos princípios normativos das ciências exatas, buscando, inclusive, uma especialização vertical. Até os anos de 1960, quando passou a agregar outros pressupostos de forma institucionalizada. Isso se deu pela "crescente incapacidade das teorias científicas mais antigas para fornecer soluções plausíveis para as dificuldades encontradas pelos cientistas [...] com fenômenos cada vez mais complexos"(Wallerstein e outros, 1996, p. 89). Diante dessa história controversa, as humanidades, as ciências sociais e as ciências da comunicação precisam buscar seus próprios caminhos.

Mais do que uma metateoria, Wallerstein e seus colegas da Comissão Gulbenkian, em "Para abrir as ciências sociais", promovem um manifesto científico, no qual apoiam-se princípios de integração dos saberes e inclusão de múltiplas experiências culturais. "Consideramos que empurrar as ciências sociais para o combate à fragmentação do saber equivale a empurrá-las na direção de um significativo grau de objetividade" (Wallerstein e outros, 1996, p. 129). Assim se fez uma reestruturação paradigmática, "aos moldes" de Kuhn, que 
beneficiou todas as humanidades. Esse relatório é extensivamente importante para pensarmos, inclusive, o campo da comunicação e uma epistemologia para chamar de sua, regada pela multiplicidade do conhecimento científico já ofertado durante os milhares de anos de sua existência.

Uma epistemologia das "ciências inexatas" firma-se especialmente na invenção dos objetos de pesquisa e nas operações lógicas estruturadas subsequentes. "A invenção nunca se reduz a uma simples leitura do real, por mais desconcertante que seja, já que pressupõe sempre a ruptura com o mesmo e com as configurações que ele propõe à percepção" (Bourdieu, 1999, p. 25). A invenção é a problematização responsável pela definição de um problema de pesquisa, que é produzido, para Bourdieu (1999), mediante a quebra das relações familiares e a criação de novas articulações; tensionar o objeto, colocálo em crise. Os métodos de pesquisa devem ser criados a partir de uma vontade heurística, as técnicas têm que ser reconhecidas a partir de suas teorias, ambos devem estar articulados ao objeto, e podem, aliás, ser requisitados pelo próprio objeto - assim se produz uma teoria do objeto. Por isso, um sistema metodológico duro, pronto para ser aplicado, mostra-se cada vez mais inútil para a pesquisa. Uma postura inventiva dá as ciências humanas o caráter de riqueza que merecem a priori.

A área das ciências da comunicação também passou pelas disputas intelectuais entre os polos das "exatas" e humanas. Um interesse científico pelos meios de comunicação, aponta Lima (2000), ganha força a partir do surgimento de uma "cultura de massa", que "não representa uma ruptura com o solo da cultura popular ou folclórica, mas apenas a industrialização dentro de seus limites" (Lima, 2000, p. 22). Mesmo assim, cultura de massa é um termo intensamente questionado no desenvolvimento das ciências da comunicação. Para Eco (1965), é um conceito genérico, impróprio e ambíguo. Em vez das generalizações propostas pelos pesquisadores de culturas de massa, investe em propostas de pesquisa multifocais. $O$ termo perde força especialmente a partir dos Estudos Culturais britânicos, numa relação mais situacional de espacialidades e temporalidades. A pesquisa em comunicação, entretanto, não se resume pela trajetória da visada cultural, ela é composta por uma história de disputas de modelos.

As primeiras teorias mais pontuais procuraram entender como se dá o sistema comunicativo, entendido até então por um formato linear, em uma instância generalizante na perspectiva dos meios massivos. Esse é o campo das teorias de autores como Lasswell, Lazarsfeld e Hovland. Daí saíram os termos "manipulação", "persuasão", "influência" e "funções" para explicar as mídias; e princípios epistemológicos que buscavam um caráter de cientificidade, a partir 
da investigação de"consequências objetivamente averiguáveis da ação dos mass media" (Rossetti, 2016, p. 6). Outra vertente teórica difundida na área foi a Escola de Frankfurt, com Adorno, Horkheimer, Habermas, Honneth e Forst. Nesse, o contextosocialcomeçaa ser aproveitado para a pesquisa. Habermas, porexemplo, é quem pensa o materialismo histórico em sua teoria de "ação comunicativa".

Essas duas escolas são exemplares no dualismo agregador entre a vertente positivista, que pensava através de um darwinismo social, e a vertente dialética, do reconhecimento multidimensional da realidade. Ambas contêm elementos que nos ajudam a compreender epistemologias incrustradas nas pesquisas atuais. A não problematização epistemológica, especialmente a partir de uma arqueologia dos saberes, tem esse problema de o pesquisador estar ingênuo em relação às teorias e utilizar certas concepções sem ter a devida noção do que elas realmente oferecem à pesquisa e ao mundo científico.

Ao longo do século $\mathrm{XX}$, as teorias da comunicação sofreram diversas incorporações, mutações e rupturas. As noções de cultura de massa foram aos poucos sendo substituídas por indústria cultural e diferenciadas de cultura popular. Os modelos foram se complexificando, a exemplo dos modelos de Lasswell, Shannon, Schramm, Jakobson e Maletzke (citados por Alsina, 1989), nos quais a mensagem, os meios e os sujeitos (receptores) têm bruscas alterações de um para o outro. Os processos comunicativo/midiático, entretanto, mantêm-se sobre a premissa linear, de evento progressivo espacial, em que uma mensagem é enviada e recebida, ponto final - uma perspectiva contaminada pelo paradigma informacional. Como aponta Wolf (2008), esses modelos têm origens industriais, são aplicações, em seu sentido mais direto, à teoria da comunicação. Esse é um paradigma que persistiu dominante por muito tempo e continua a permear as pesquisas atuais, apenas com novas roupagens; a exemplo das teorias ciberculturais e interacionistas.

Por ter sido desenvolvida a partir de adaptações de modelos físicos e matemáticos, de traduções de paradigmas biológicos e de aplicações industriais - o conjunto dessas operações é chamado pelos Mattelart (2004) de paradigma mecânico -, a área das ciências da comunicação é carente de epistemologias. A comunicação vista como função, especialmente a partir de uma racionalidade publicitária apresenta-se como uma perspectiva em favor da precariedade de nossas pesquisas e do campo como um todo. É resultado primordial de uma visão neoliberal, da globalização hegemônica, da descentralização e do empreendedorismo como "novo modo de captação de energias" (Mattelart, 2004, p. 206). É evocado pelo discurso darwinista, das formas sociais naturais, em que "o melhor vence" (p. 212), subvertendo as lógicas, quando permite afirmar que o mercado é mais progressista do que os movimentos sociais. Apropria-se 
de termos bonitos como modernização, inovação, difusão e participação para ampliar sua base de negociação, especialmente, econômica. Essa narrativa, que penetra nas teorias daárea, prejudica a memória popular, as comunicaçõescontrahegemônicas, a história das classes trabalhadoras e dos oprimidos em geral, atropela as noções de direitos humanos, liberdade, igualdade e fraternidade, e, principalmente, procura anular a ação do sujeito, tornando-o mero consumidor.

Os Mattelart (2004) explicam, entretanto, como há uma curva em toda essa história, ou pelo menos uma narrativa da resistência, em que o paradigma fluído "vence" a lógica mecânica - há aí, uma "virada epistemológica" (Mattelart, 2004, p. 85). Essa superação ocorre justamente pelo desenvolvimento epistemológico transdisciplinar que flutua como um espírito pelas pesquisas das várias ciências. Muitos pesquisadores se nutriram dessas fontes para quebrar as correntes neolatifundiárias das teorias, até o momento em que era impossível negá-los, pois seus escritos muito inteligentes e perspicazes atingiam uma coerência teórica fundamental. É o caso de Winkin, quando dizia que "é em termos de níveis de complexidade, de contextos múltiplos e de sistemas circulares que é preciso conceber a pesquisa em comunicação" (Mattelart, 2004, p. 106). Só para citar o levantamento dos Mattelart (2004): Foucault contribui com suas pesquisas sobre os micro-poderes, Gramsci com o conceito de hegemonia e Certeau com seus exames quase microbianos do cotidiano. Isso tudo leva a pesquisa em comunicação a olhar com mais cuidado para uma dimensão dos processos midiáticos em especial, a do sujeito.

Essasvertentesalternativas têm produzido pesquisas que elevamo padrão dos estudos em comunicação, atravessando com maior perícia os mais diversos campos sociais, e compreendendo os vários papéis de atuação e participação das mídias na vida social. Na pesquisa de Peruzzo (2016, p. 6)), por exemplo, "se reconhecem os atores investigados como sujeitos (coletivos ou individuais) e a potencialidade de construção de conhecimento científico na relação com os mesmos na condição de participantes ativos, como co-protagonistas"; uma forma frutífera de articular teorias transdisciplinares aos fenômenos problematizados. Na construção de sua proposta de "pesquisa-ação", Peruzzo (2016, p. 5) fala sobre uma epistemologia do sul, que busca a compreensão das realidades em outros conhecimentos além do científico, "o reconhecimento de outros saberes - dentro das lógicas e das necessidades dos povos do continente latino-americano". A metáfora do sul refere-se especialmente a América Latina, onde finalmente, depois de séculos de colonialismo, não só as elites têm oportunidades de ingressar no campo acadêmico, mas uma população mais abrangente tem possibilidades de construir teorias. Desses novos participantes 
dos processos científicos, percebe-se uma necessidade intensa, de uma transformação da realidade latino-americana.

\section{Transformar a América Latina}

A epistemologia une racionalidades temporais e espaciais. Na América Latina, há uma necessidade iminente de se criar novas epistemologias voltadas às experiências e à vida na região, consciente de suas virtudes, de seus problemas e de seus desafios. Epistemologias plurais renovadoras das práticas sociais, que busquem intervenções nos espaços públicos e privados, utilizando os instrumentos à mão como as duas outras dimensões universitárias, do ensino e da extensão. Epistemologias de integração com outros países ao sul, como dos continentes africano e asiático, trocas provocadoras de ensinamentos a todos; de uma transferência tecnológica, podemos começar a falar em transferência epistemológica. Antes de construirmos um campo das ciências da comunicação capaz de responder às nossas problemáticas e que produzam o conhecimento necessário para os habitantes de nossos países, é preciso aquilo que Morawicki (2016) chama atenção: a descolonização das teorias.

Se olharmos os trabalhos publicados nos mais variados meios de divulgação científica, as produções de pesquisa latino-americanas estão concentradas em referências de autores estadunidenses e europeus. Há sim uma contracorrente relevante nas últimas décadas, porém, ainda é preciso fortalecer epistemologias localizadas nas espacialidades e nas temporalidades de nossa região. Diferentemente de algumas ciências "exatas", que analisam elementos universais da natureza, nossos objetos são construídos sob égides históricas, localizadas, sofrem pressão de jogos de poder, aparecem sobre lógicas múltiplas, que necessitam serem problematizadas e articuladas com teorias próprias. Mais do que uma proposta vazia, ela está baseada na situação histórica, política, econômica, social e cultural da América Latina. O campo das ideias na região tem sido um grande mercado das companhias globais, de seus think tanks, da importação de talentoslatino-americanos e de neutralização do campo científico. Morawicki (2016) explica como isso se dá na Argentina, numa articulação entre os campos de Comunicação e Educação. Na pesquisa, identificou que, apesar de ter havido progresso nessas áreas, desde a década de 1990, em matéria epistemológica, não houve avanço no sentido de romper com o "imperialismo pedagógico" das práticas individualizantes, e isso é "um aspecto fundamental dos processos de dominação ou de articulação hegemônica" (Morawicki, 
2016, p. 355, tradução nossa)2. Morawicki (2016) afirma que as investigações precisam descortinar esses processos e produzir novas alternativas e saberes:

[...] uma investigação teórica ou epistemológica está politicamente equilibrada na natureza estratégica da tradição acadêmica e institucional do qual este tema de pesquisa surge: a crença de que a comunicação e a educação devem ser campos que superem a dicotomia pragmatismo/teoricismo, o que implica na construção de uma metodologia de intervenção social dentro de uma rigorosa e explícita plataforma epistemológica (Morawicki, 2016, p. 356, tradução nossa) $)^{3}$.

Para abrir um novo campo epistemológico, é preciso observar as condições do espírito global que paira sobre nós: o capitalismo; para Sodré, "turbo-capitalismo", em que"a dominância ideológica são as finanças, no mundo inteiro" (Grohmann, 2015, p. 121). Há, nesse sentido, uma grande hegemonia do mundo financeiro relativa a outros campos de sociabilidade e à vida direta de todos os habitantes do planeta. As condições de moradia, de segurança e de cidadania estão gravemente sujeitas aos acordos unilaterais entre as sociedades e os donos dos capitais transnacionais - uma pressão desenfreada de $1 \%$ da população sobre o restante. Essa dinâmica atravessa o campo da comunicação, tornando as empresas midiáticas, como forte vetor de constrangimento sobre a sociedade, construtoras de mercados, ativas no sentido de promover seu desenvolvimento monetário. "A consciência individualista se sobrepõe no espaço público à consciência solidária, gerando condições desfavoráveis à quaisquer novas estratégias de institucionalização dos direitos sociais" (Sodré, 2015, p. 136). Nessa ideologia financeira, a cidadania e as sociabilizações são impressas unicamente através de práticas de consumo. Isso gera a necessidade de um deslocamento.

Em uma sala de cinema de Cali, Martín-Barbero (2008) conta quando teve um "calafrio epistemológico". Durante um filme de melodrama, que para ele era pitoresco, alguns sujeitos se emocionavam intensamente com cada cena. A situação indagou-lhe: "o que tem a ver o filme que eles veem e o que eu vejo?" (Martín-Barbero, 2008, p. 30, tradução nossa)4. Naquele momento, o pesquisador precisou de um deslocamento, estabelecer novas perguntas -

2 Original: "un aspecto fundamental de los procesos de dominación o de articulación hegemónica".

3 Original: "una investigación teórica o epistemológica está políticamente contrapesada en el carácter estratégico que la tradición académica e institucional desde la cual se origina este tema de investigación: la convicción de que Comunicación y Educación debe ser un campo que supere la dicotomía pragmatismo/teoricismo, lo cual implica la construcción de una metodología de intervención social dentro de una rigurosa y explícita plataforma epistemológica".

4 Original: "¿qué tiene que ver la película que yo estoy viendo con la que ellos ven?". 
uma ruptura epistemológica. “E a mudança metodológica indispensável, feita pela abordagem do estranhamento etnográfico e do distanciamento cultural, que permitiria ao pesquisador a ver com as pessoas, e as pessoas contarem o visto" (Martín-Barbero, 2008, p. 30, grifos do autor). A partir daí, Martín-Barbero passou a observar os fenômenos comunicativos de grande popularidade, em especial as telenovelas, pela sua disposição estratégica na cultura cotidiana das maiorias, com uma nova ótica, a partir de uma epistemologia aberta. As investigações subsequentes deram pistas sobres as novas sensibilidades, estéticas, lógicas de poder, discursos e narrativas que circulavam entre as mídias, as culturas populares, os governos, a globalização, e dão pistas essenciais para a problematização da financeirização.

Martín-Barbero é um dos exemplos de pesquisador que buscou o enfrentamento epistemológico e a superação das teorias do norte. Sua sistematização sobre as mediações foi um marco e continua sendo fundamental para a compreensão das realidades de nossa região e suas interconexões com os contextos midiáticos. Uma teoria para abrir os olhos às mediações que atravessam os processos sociais, localizando e identificando suas características e temporalidades. Com as mediações, principalmente, é possível planejar novos modos de ser e de se produzir comunicação na região. Seus "mapas noturnos" lhe trouxeram a noção dos processos comunicativos como palimpsestos, e isso nos ajuda a pensar sobre novos modos contra-hegemônicos, capazes de distribuir posições de fala. "A comunicação será alternativa à medida que se assume a complexidade desses processos; isto é, se junto da linguagem do meio se investigue os códigos de percepção e reconhecimento, os dispositivos de enunciação do popular" (Martín-Barbero, 1988, p. 22).

Nós, latino-americanos, vivemos em um espaço/tempo que nos pede não apenas o avanço irrestrito das ciências, sua propulsão em números ou em qualidade, mas requisita ciências transformadoras, pesquisas para, em vez de decretar seu fim, reinventar a história. Como aponta Santos (2010, p. 84), “os poderes hegemônicos que comandam a globalização neoliberal, a sociedade de consumo e a sociedade de informação têm vindo a promover teorias e imagens que apelam a uma totalidade", e essa é a verdadeira sangria necessária de ser estancada.

A comunicação e a cumplicidade epistemológica assentam na ideia de que não há só uma forma de conhecimento, mas várias, e de que é preciso optar pela que favorece a criação de imagens desestabilizadoras e de atitudes de inconformismo perante elas. (Santos, 2010, p. 85). 
É através de uma cadeia fechada de saberes e valores que o capitalismo, enquanto virtualidade, costura as dinâmicas sociais ao redor do globo, forçando a adesão única de sua própria epistemologia - e consequentemente seus resultados de concentração de renda, miséria, violência, individualismo, autoritarismo, dentre muitas outras manifestações nocivas a cidadania dos sujeitos. Uma epistemologia na América Latina não pode estar voltada a outro fim que não a promoção dos direitos humanos, da cidadania, da solidariedade, e em suma, à independência da região em relação às garras do sistema de poderes transnacionais do mercado neoliberal. A luta contra a financeirização é uma luta não contra a globalização, processo irrevogável e necessário para a coletividade das civilizações humanas, mas contra um tipo específico de sua manifestação: "globalização hegemônica, como o processo através do qual um dado fenômeno ou entidade local consegue difundir-se globalmente e, ao fazê-lo, adquire a capacidade de designar um fenômeno ou uma entidade rival como local" (Santos, 2010, p. 86). Essa capacidade de produzir hierarquias pode ser impedida a partir da criação de visões autônomas, de valorização dos patrimônios históricos e culturais regionais, de aberturas de canais e vínculos com outras "nações do sul", e outras estratégias promotoras da inter-relação entre conhecimento e solidariedade.

Para reinventarmos a história e a própria região, é preciso reinventar todos os sistemas e processos científicos a partir de uma base transmetodológica (Maldonado, 2013). Esse princípio epistêmico alternativo, pensado desde a América Latina, propõe "abordagens metodológicas multifocais" (Maldonado, 2013, p. 32), "entrelaçamento de lógicas diversas (formais, indutivas, paraconsistentes, abdutivas, experimentais e inventivas); estruturação de estratégias, modelos e propostas mistas, midiáticas, que inter-relacionem os vários aspectos das problemáticas sociais" (Maldonado, 2013, p. 33). Somente propostas que tenham a capacidade de averiguar a complexidade das dimensões comunicativas, midiáticas, sociais (culturais, econômicas, políticas, históricas), é que podem dar conta da articulação entre ciência e o mundo da vida. Essa epistemologia requer do sujeito pesquisador uma bagagem de estudos rica de variedade, de profundidade, de conhecimento das dimensões que fazem parte de seu objeto de pesquisa, e, especialmente, das configurações diacrônicas dos "modos de vida midiatizados" (Maldonado, 2013, p. 35). Diante da complexidade desse desafio, "transformar-se ou perecer é uma necessidade dialética" (Maldonado, 2013, p. 38). É necessário produzir práxis teóricas, novos instrumentos de pesquisa e apropriar-se das técnicas disponíveis. E mais do que a produção de conceitos, a ciência deve buscar participações heurísticas, modos de intervenção social, operacionalização das teorias e técnicas produzidas em 
aproximação com coletivos e comunidades. Não apenas produzir problemas de conhecimento, mas divulgá-los, expor sua importância diante de um mundo carente de ideias desestabilizadoras.

\section{Considerações finais}

Neste texto, tratamos de epistemologias, problemas filosóficos, políticos, sociais, culturais, comunicativos e científicos da ciência, um panorama arqueológico, e novos modos de perceber as relações entre a academia e as sociedades que as cercam. Entendemos que apenas a ampliação da bagagem científica nos permitirá acessar nossos objetos de forma completa e nos voltarmos a uma produção teórica frutífera e transformadora. Somente o conhecimento histórico, diacrônico e arqueológico, dos paradigmas teóricos, metodológicos e epistemológicos, nos dará a segurança necessária para produzir conhecimentos valorosos. O entendimento das noções ideológicas por trás desses movimentos teórico-epistemológicos também se torna fundamental na medida em que as civilizações vivem num atrito multipolarizado de princípios, éticas, morais e valores, e em que as elites e os poderes transnacionais têm conseguido estabelecer hegemonias de conhecimento. Vimos como as ciências humanas encontram seu papel justamente na decodificação de um mundo em vias de globalização hegemônica, de financeirização, e todo o conjunto de problemáticas atrelados a esses processos, e na produção de alternativas com vistas a horizontes de solidariedade e cidadania.

Propomos aqui novas epistemologias para a pesquisa em comunicação, que abandonem a ideia das massas, de receptores, de audiências amorfas, em favor da construção teórica voltadas ao entendimento dos sujeitos e seus modos comunicativos, numa perspectiva de profícua relação entre objeto e teoria. Em vez das antigas aplicações unívocas das ciências sociais, e suas atualizações pelo marketing no século XXI, dos surveys e demais práxis funcionalistas, propomos a reintegração da pesquisa ao mundo da vida, a produção teórica de acordo com o processo comunicativo como ele realmente é, em seu complexo devir. A dimensão política da pesquisa e da comunicação é uma das principais mediações, nesse sentido, pois é através dos poderes institucionalizados que as formas comunicativas são idealizadas e postas em prática. A América Latina é um laboratório muito diversificado de práticas comunicativas, produzindo exemplos restritivos, de oligopólios, como o caso brasileiro, e modelos alternativos com a "lei de meios" (2009-2016), da Argentina. Ao mesmo tempo em que nos mostra um momento histórico disruptivo, o caso Venezuelano; é de suma importância produzirmos pesquisas para entender os conflitos desse caso, para entendermos as contradições entre as oligarquias e a democracia, e 
fundamentarmos novas teorias e relações, com vistas à renovação cidadã da América Latina.

No caminho transmetodológico, "os sujeitos pesquisadores, os cientistas formam-se no cultivo dos desafios do rigor, da aventura, da arte, da disciplina teórico/metodológica, da crítica e da invenção de processos transformadores do mundo e da vida" (Maldonado, 2013, p. 45). De certa forma, vínhamos construído uma epistemologia transdisciplinar desde os primeiros movimentos reflexivos deste texto, a partir da união, do tensionamento, da montagem, do conflito de ideias e propostas, sempre relacionando com o mundo da vida e da pesquisa. Já foi com essas ideias que ingressamos no desafio de articular e incitar epistemologias inventivas desde nossa região latino-americana, a fim de quebrar também com o monopólio de reflexões produzidas pelas elites.

Nesse sentido, concluímos com um manifesto em relação a nossa ciência e à cidadania científica. Entre nossas anotações sobre o texto de Japiassu (1991), apareceu a seguinte sentença: "a academia é tudo o que ela critica: da meritocracia à escala industrial". Apesar de haver movimentos de exceção, o darwinismo social tem sido a epistemologia fundante da ciência no Brasil, e a produção científica vinda desse sistema também está virtualmente articulada às práticas de produção em série. Seja nas experiências dos eventos científicos, que amontoam apresentações sem horizontalidades ou a devida atenção reflexiva, seja no volume de produção cobrada de discentes e docentes para abastecer seus currículos como forma obrigatória de acesso aos espaços institucionalizados, a quantidade apresenta-se acima da qualidade. Essas duas situações não promovem as transformações epistemológicas que suscitamos necessárias na América Latina. Novas condições precisam ser criadas a partir da universalização irrestrita da educação, não como mercadoria, mas como virtude social básica, e a partir de novos mecanismos de quantificação solidária e cidadã, num sistema mais humano, menos industrial calculado. Somente quando todos os sujeitos latino-americanos tiverem oportunidades, com a devida motivação de transformação, é que conheceremos o campo científico renovado, bem como uma nova América Latina. 


\section{Referências}

BOURDIEU, Pierre; CHAMBOREDON, Jean-Claude; PASSERON, Jean-Claude. Ofício de sociólogo. Tradução de Guilherme João de Freitas Teixeira. Petrópolis: Editora Vozes, 1999.

CASSIRER, Ernst. El problema del conocimiento. Tradução de Wenceslao Roces. México: Fondo de Cultura Económica, 1993.

ECO, Umberto. Apocalípticos e integrados. Madrid: Editorial Lumen, 1965.

GROHMANN, Rafael. A comunicação eletrônica é epistemológica. Entrevista com Muniz Sodré. Revista Parágrafo, São Paulo. v. 1, n. 3, p. 120-127, jan./jun. 2015. Disponível em: http://revistaseletronicas.fiamfaam.br/index.php/recicofi/ article/view/289/296. Acesso em: 12 jul. 2017.

HABERMAS, Jürgen. $\mathbf{O}$ discurso filosófico da modernidade. Tradução de Luiz Sério Repa e Rodnei Nascimento. São Paulo: Martins Fontes, 2000.

HALLER, Rudolf. Wittgenstein e a filosofia austríaca:Questões. São Paulo:EDUSP, 1990.

JAPIASSU, Hilton Peneira. Introdução ao pensamento epistemológico. 6. ed. Rio de Janeiro: Francisco Alves, 1991.

KUHN, Thomas. A estrutura das revoluções científicas. Tradução de Beatriz Viana Boeira e Nelson Boeira. 5. ed. São Paulo: Editora Perspectiva, 1998.

LIMA, Luiz Costa. Teorias da cultura de massa. 6. ed. Rio de Janeiro: Paz e Terra, 2000.

MALDONADO, Alberto Efendy. A perspectiva transmetodológica na conjuntura de mudança civilizadora em inícios do século XXI. In: ; BONIN, Jiani Adriana; ROSÁRIO, Nísia Martins. Perspectivas metodológicas em comunicação: novos desafios na prática investigativa. Salamanca, Espanha: Comunicación Social Ediciones y Publicaciones, 2013.

MARTÍN-BARBERO, Jesús. Comunicación y culturas en América Latina. Revista Anthropos: Huellas del conocimiento, n. 219, 2008.

- Retos a la investigación de comunicación en América Latina. In:

Procesos de comunicación y matrices de cultura: itinerarios para salir de la razón dualista. Barcelona: Gustavo Gili, 1988.

MATTELART, Armand; MATTELART, Michèle. Pensar as mídias. São Paulo: Edições Loyola, 2004.

MORAWICKI, Kevin. Matrices teóricas y políticas en el campo de la comunicación y educación en Argentina. In: XIII CONGRESO LATINOAMERICANO DE INVESTIGADORES DE LA COMUNICACIÓN, 2016, Cidade do México. 
Memorias. Cidade do México: Universidad Autónoma Metropolitana, 2016. Disponível em: <http://alaic2016.cua.uam.mx/documentos/memorias/GT4. pdf>. Acesso em: 12 jul. 2017.

MORIN, Edgar. 0 método 3: conhecimento do conhecimento. Porto Alegre: Sulina, 2008.

NORRIS, Christopher. Epistemologia: conceitos-chave em filosofia. Porto Alegre: Artmed, 2007.

PEIRCE, Charles Sanders. A fixação da crença. Tradução de Anabela Gradim. 1997.

PERUZZO, Cicília. Epistemologia e método da pesquisa ação: uma aproximação aos movimentos sociais e à comunicação. In: XXV ENCONTRO ANUAL DA COMPÓS, 2016, Goiânia. Anais eletrônicos... Goiânia: Universidade Federal de Goiás, 2016. Disponível em: <http://www.compos.org.br/ biblioteca/epistemologiaemétododapesquisa-ação...ciciliaperuzzo. modelocompos2016._3270.pdf>. Acesso em: 12 jul. 2017.

POPPER, Karl Raimund. Conhecimento objetivo. Belo Horizonte: Ed. Itatiaia; São Paulo: EDUSP, 1975.

RODRIGO ALSINA, Miquel. Los modelos de la comunicación. Madrid: Tecnos, 1989.

ROSSETTI, Regina. Mudanças teóricas nas trajetórias de funcionalistas e frankfurtianos. In: ENCONTRO ANUAL DA COMPÓS, 25. 2016, Goiânia. Anais eletrônicos... Goiania: Universidade Federal de Goiás, 2016. Disponível em: <http://www. compos.org.br/biblioteca/2016mudançasteóricascompos_3364.pdf>. Acesso em: 13 jul. 2017.

SANTOS, Boaventura de Sousa. Gramática do tempo: para uma nova cultura política. São Paulo: Cortez, 2010.

SODRÉ, Muniz. Mídia, ideologia e financeirização. Oficina do historiador. Porto Alegre, v. 8, n. 1. p. 134-157. 2015.

WALLERSTEIN, Immanuel. e outros. Para abrir as ciências sociais. Lisboa: Publicações Europa-América, 1996.

WOLF, Mauro. Teorias das comunicações de massa. São Paulo: Martins Fontes, 2008. 
Dados dos autores:

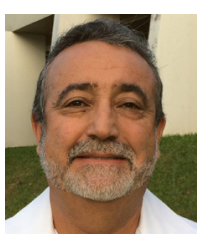

Alberto Efendy Maldonado Gómez de la Torre | efendymaldonado@gmail.com Universidade do Vale do Rio dos Sinos (UNISINOS)

Doutor em Ciências da Comunicação pela USP. Professor/pesquisador do PPGCC-UNISINOS e titular da Cátedra Armand Mattelart, CIESPAL.

Endereço do autor:

Programa de Pós-Graduação em Ciências da Comunicação da Universidade do Vale do Rio dos Sinos (PPGCC-UNISINOS)

Av. Unisinos, 950 - Bairro Cristo Rei

93.022-750- São Leopoldo, RS, Brasil

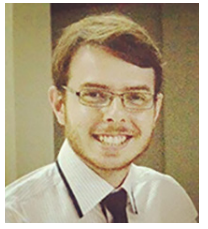

Julherme José Pires | julherme.pires@gmail.com

Universidade do Vale do Rio dos Sinos (UNISINOS)

Doutorando no PPGCC-UNISINOS. Membro da Rede AMLAT e dos

grupos de pesquisa PROCESSOCOM e TCAv.

Endereço do autor:

Programa de Pós-Graduação em Ciências da Comunicação da Universidade do Vale do Rio dos Sinos (PPGCC-UNISINOS)

Av. Unisinos, 950 - Bairro Cristo Rei

93.022-750- São Leopoldo, RS, Brasil

Contribuições dos autores: Ambos os autores fizeram contribuições substanciais para concepção, desenvolvimento, redação e revisão crítica do trabalho; e aprovação final da versão para publicação. 